\title{
Effects of age and ingestive experience on air-drinking behavior in the rat,'?
}

\author{
DAVID C. RICCIO, DAN M. HAMILTON AND F. ROBERT TREICHLER
}

KENT STATE UNIVERSITY

Thirsty rats $18,23,30$, or 40 days old received a brief air puff when they licked at a tube. Air-drinking occurred even in 18 day $S s$, and increased significantly as a function of age. In a second experiment, rat pups reared without access to a water bottle were similarly tested for air-drinking behavior at 18 or 23 days. Operant level of tube licking was determined for litter mates. Significantly greater tube licking occurred in air reinforced Ss, indicating that prior experience with drinking water from a tube was not a necessary condition for the establishment of air-drinking behavior.

Hendry \& Rasche (1961) have demonstrated that thirsty rats will lick at a stream of air delivered through a drinking tube and that this may serve as a reinforcing stimulus. More recently, Williams, Treichler, \& Thomas (1964) showed that prolonged free exposure to an air tube produced only moderate satiation effects on subsequent bar pressing for air.

The persistence of responding for air in the absence of the usual identifiable primary reinforcers suggests that the air stream may be either innately or secondarily reinforcing. Since adult rats have typically been used, the extent to which air-drinking is influenced by prior experience with water drinking is not known. If air-drinking depends upon providing stimulus properties similar to drinking water from a tube, almost no air-drinking would be expected to occur in preweanling Ss. The aim of this study was to determine whether air drinking behavior was dependent upon maturational level and ingestive experience.

\section{EXPERIMENT 1}

\section{Method}

The Ss were 24 Holtzman rats at four different age levels. The test apparatus consisted of an $8 \times 9 \times 10$ in. chamber with a stainless steel drinking tube extending $1 / 4 \mathrm{in.}$ into the cage and located 1 in. above the floor. Air was supplied through a compressed air line and a moisture trap after being reduced to $3 \mathrm{lb} / \mathrm{in} .^{2}$

Six Ss at each age: $18,23,30$, or 40 days old comprised the four test groups. The 18 day old animals provided a preweanling group. All Ss were weaned at 21 days and placed in individual home cages. Two additional groups of 18 and 23 day old rats provided a baseline for operant level of tube contact (see Experiment 2 Method).

Prior to air-drinking measurement each experimental $S$ received two daily 1-hr. adaptation sessions with a continuous stream of air present. Adaptation and test periods were conducted under water deprivation since this condition appears necessary for airdrinking (Hendry \& Rasche, 1961). In order to produce comparable water deficits, periods of $6,10,21$, or $24 \mathrm{hr}$. of privation were imposed to reduce $\mathrm{Ss}$ of each age to about $90 \%$ of original weight. It has been shown that proportional reductions in body weights match drive levels in animals of different ages (Camphell \& Cicala, 1962).
Deprivation was effected by a period of caging apart from the mother for 18 day Ss and by removal of the water bottle for the older groups.

Test sessions consisted of $30 \mathrm{~min}$. periods on two successive days when contacts with the tube produced $.1 \mathrm{sec}$. air presentations. An apparatus failure resulted in loss of data from two 30-day Ss.

Results

Figure 1 presents the median total responses in the two test sessions as a function of age. The early occurrence of air-drinking is indicated by comparison of the response rates for the preweanling (18 day) group and the operant levels of similar Ss. A MannWhitney $\mathrm{U}$-test indicated significant differences between the numbers of operant level and puff producing responses ( $p=.008$, two-tailed test). Further, a KruskalWallis analysis demonstrated significant $(p<.001)$ differences among the numbers of responses at the various ages with response rates appearing to reach an asymptotic level around 30 to 40 days.

\section{EXPERIMENT 2}

Hendry \& Rasche (1961) proposed that air-drinking may represent a failure of the rat to discriminate

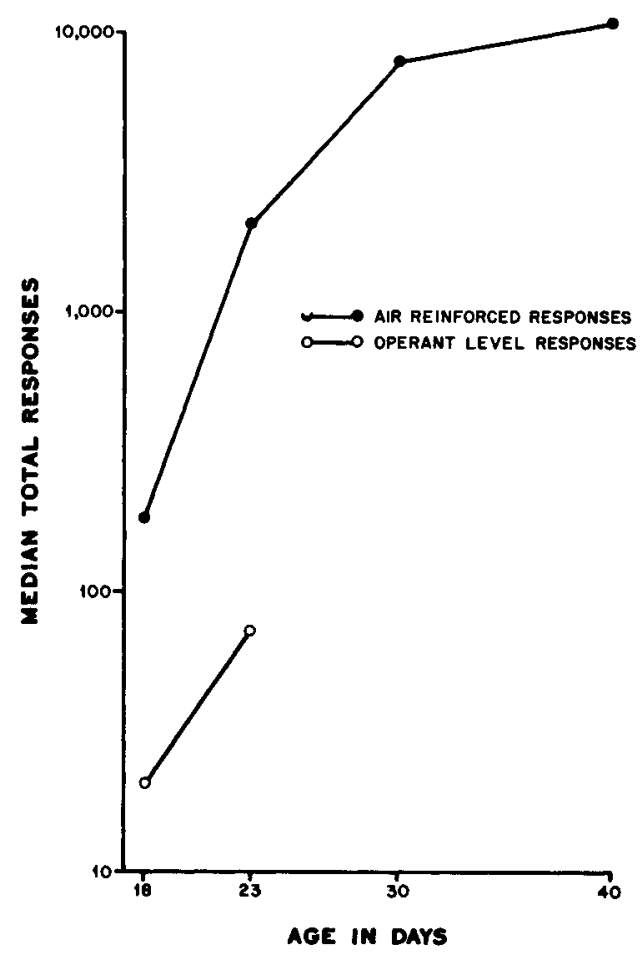

Fig. 1. Tube contacting responses as a function of age. 


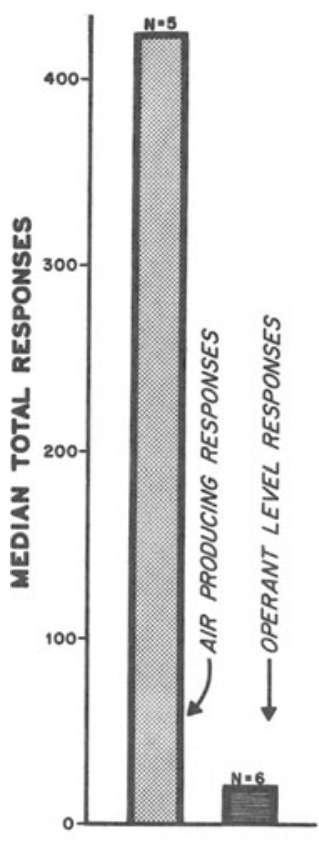

18 DAY $\underline{\text { s }}$

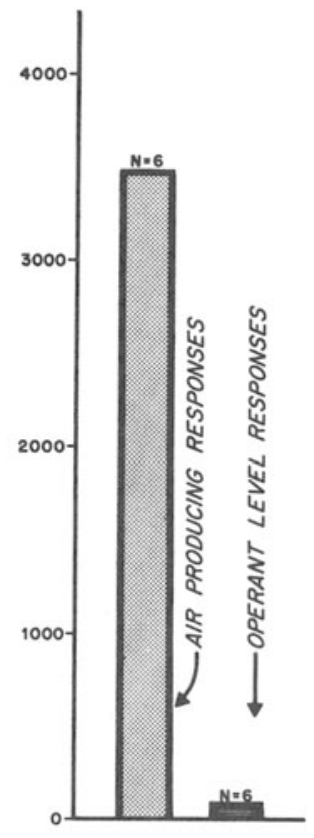

23 DAY $\underline{\text { s }}$
Fig. 2. Tube contacting responses in 18 and 23 day rats reared without a water bottle.

between sensory qualities common to water and air. This contention does not specify whether the reinforcing properties of air are dependent upon innate or learned factors. A learning interpretation would suggest that particular sensory qualities are first associated with obtaining water and, because an air stream provides similar stimulation, it comes to serve as a secondary reinforcer. Conversely, if reinforcement were innately organized, no prior water drinking experience would be necessary for airdrinking to occur.

While the presence of air-drinking in the preweanling $S_{8}$ of Experiment 1 might seem to negate a secondary reinforcement interpretation, some of these Ss were observed to lick the water tube. Thus, it was possible that a brief and limited water drinking experience provided a sufficient basis for establishing a later "water-like" sensory effect. The aim of Experiment 2 was to determine whether prior water drinking experience was a necessary condition for the establishment of air-drinking behavior.

Mothod

The Ss consisted of four litters of Holtzman rats 10-12 days old purchased with their mothers. The apparatus was the same as that of Experiment 1. Rat pups reared without access to a water bottle by periodically giving their mothers water in separate cages were tested on air-drinking at 18 or 23 days. To determine the operant level of tube contact, litter mates of the experimental Ss were measured when no air stream was delivered.

As in Experiment 1, age dependent deprivation durations were imposed and two daily 1-hr. air adaptation sessions were provided. Similarly deprived operant level control groups received the same exposure time in the test chamber without an air stream. Omission of the air served to adapt Ss to the apparatus without adventitiously reinforcing tube licking.

Following adaptation sessions, the number of tube contacts made by each $S$ was recorded in $30 \mathrm{~min}$. tests on each of the next two days. The operant level groups received no air puff after contact with the tube.

\section{Results and Discussion}

Figure 2 presents median total contacts for the two sessions for 18 and 23 day Ss maintained without a water bottle under air presentation or operant control conditions. A Mann-Whitney U-test indicated that differences between these groups were significant at both ages $(p=.018$ and $p=.002$, two-tailed tests). No significant differences were found between rearing with (Experiment 1) or without (Experiment 2) access to a water bottle in either 18 or 23 day old $S s(p=.18$, $\mathrm{p}=.31$, Mann-Whitney two-tailed tests).

The results indicate that licking at a stream of air serves as a non-nutritive reinforcer for thirsty rats even at early stages of development. The higher response rate in older Ss may represent either changes in reinforcing value as a function of age or a physical inability of young $S s$ to maintain rapid licking.

While the basis for air-drinking as a reinforcer is not defined by these data, some possibilities appear to be excluded. The establishment of air-drinking behavior is not dependent upon prior experience in drinking water from a tube. The reinforcing aspects of air-drinking, if based upon conditioned reinforcing properties, must be associated with very early feedings by the mother. Air-drinking's apparent independence from experiential factors indicates that the sensory consequences of air in the mouth are reinforcing.

\section{References}

Campbell, B. A., \& Cicala, G. A. Studies of water deprivation in rats as a function of age. J. comp. physiol. Psychol., 1962, 55, 763-768.

Hendry, D. P., \& Rasche, R. H. Analysis of a new non-nutritive positive reinforcer based on thirst. J. comp. physiol. Psychol., $1961,54,477-483$.

Williams, J. L., Treichler, F. R., \& Thomas, D. R. Satiation and recovery of the "air-drinking" response in rats. Psychon. Sci., 1964, $1,49-50$.

\section{Notes}

1. The authors gratefully acknowledge the assistance of Carolyn $\mathrm{K}$. Erickson, Patricia Gessler and Norma Haggberg.

2. Portions of this paper will be presented at the Eastern Psychological Association meeting. Boston, 1967. 